days the pseudo-patients were discharged with a diagnosis of "schizophrenia in remission". On the basis of this and a number of related pranks, Rosenham concluded that "It is clear that we cannot distinguish the sane from the insane in psychiatric hospitals". Very amusing, no doubt, but normal people who are not in the pay of psychologists either don't hear The Eysencks themselves quote Seymour Kety's withering comment - " "If I were to drink a quart of blood and, concealing what I had done, come to the emergency room of any hospital vomiting blood, the behaviour of the staff would be quite prehaving a bleeding peptic ulcer, I doubt that I could argue convincingly that medical science does not know how to diagnose that condition" - but they are not thereby inhibited from describing Rosenham's jest as a "key experiment".

Not all of the selections are as silly as Rosenham's study. The book contains quite sensible sections on eye-witness testimony, divided attention and forto teach sign language to chimpanzees is an improvement on many popular treatments of the topic. But these islands of sanity are lost in the surrounding sludge of trivia and titillation. What can one say of a book which proclaims that psychology should "be regarded as the most important of all the sciences" and then reports that "Small breasts were preferred by men with fundamentalist religious beliefs suffering from mild depression"'? voices or, if they do, are not sufficiently worried by it to seek admission to hospital. dictable. If they labelled and treated me as getting. Similarly, the chapter on attempts

There is little improvement when the Eysencks draw out the practical implications of their choice of topics. We are informed that a process of conditioning can turn our children into "wellintegrated, honest members of society" and referred to Chapter 6 for the experimental evidence that this is so. Chapter 6, however, reports that obsessive and compulsive disorders can be treated by "behaviour therapy". In Chapter 22, a discussion of Hans Eysenck's "theory" of personality is held to support the claim that "The egalitarian principle underlying socialism is in conflict with biological reality and can only be enforced by dictatorship". Exactly how this conclusion is reached remains shrouded in mystery. An appallingly ill-controlled "experiment" on the effects of two types of play-group prefaces the remark that "the advocates of progressive teaching. . have turned our pre-school groups, kindergartens and primary schools into permissive places of no work and all play, from which all socializing and restraining influences have been banned".

One can only hope that this grubby little opus will sink without trace. It totally fails to represent those aspects of psychology where results of some intellectual depth have been obtained in the study of perception, language and skilled action; it similarly ignores many areas of occupational, clinical and educational research where careful, thoughtful work has served to enhance the quality of life.

John C. Marshall is in the Neuropsychology Unit, part of the Neuroscience Group at the Radctiffe Infirmary, Oxford.

\section{Find the (North American) bird}

\section{Clayton M. White}

The Audubon Society Encyclopedia of North American Birds. By John K. Terres. Pp.1,109. ISBN 0-3944-6651-9. (Knopf: 1980.) \$60 US only.

IN 1896 Professor Alfred Newton published his Dictionary of Birds. Thus a mould was cast. But it took another 68 years, until 1964, through the British Ornithologists' Union and under the editorship of A. Landsborough Thomson, for another such work to appear: $A \mathrm{New}$ Dictionary of Birds. Now, only 16 years later, another giant encyclopaedia is on the market. To me, this current volume appears to be an attempt to update a considerable body of material from the now elusive New Dictionary. Its scope, however, is mainly restricted to North America.

The book is designed to be a singlevolume work for both layman and professional, but I suspect the lay will benefit most. There are nearly 6,000 alphabetically arranged entries and cross references, illustrated with 875 full-colour photographs of bird species and over 800 black-and-white drawings. The scope of the entries is impressive: Birdhouse, Bird Lice, Birds as Collectors, Birds as Watchdogs, Bird Skin, Bird-Watcher, Bisexuality, Bittern, Blackburne, among the "B's" for example. Abbreviated life histories of 847 birds are provided. For each species are given a description of the Latin or Greek origin of the scientific name (a most valuable feature), the bird's geographical range, colour and distinctive morphological features, habitat, feeding habits, other names, nest, eggs, and other features of interest (such as who parasitizes whom). Terres cites over 4,000 references, ranging in date from the turn of the $1800 \mathrm{~s}$ to 1980 , all of which are listed in a bibliography. The bulk of several alphabetical sections is taken up by species accounts. The taxonomic treatment is fairly current by both European and American standards, at least in common names, but is more conservative and departs somewhat from the nomenclature of Peter's
Check-list of Birds of the World. For example, Terres leaves the titmouse family intact and includes the long-tailed tits (Aegithalinae) and penduline tits (Remizinae) as subfamilies rather than treating them as distinct families as has been recently practised. On the other hand, the thrushes are retained in their own family, Turdidae, and there is no mention of their current placement as a subfamily in the Old World flycatcher family, Muscicapidae.

While the book has many virtues it falls short of the stated goal of providing information on all the birds that have nested or been sighted in Alaska, Canada, Greenland, Bermuda, Baja California and the 48 contiguous states of the USA. Omissions are conspicuous, for example, in the Alaskan avifauna. While the 1978 update of the status of Alaskan birds is referenced in numerous places, and 1980 Alaskan references are also given, it is annoying that no less than 22 Alaskan species given in the 1978 publication are ignored. For instance, while the willow warbler (an Old World warbler) is discussed, nothing is said about its North American status. Only its Eurasian distribution is mentioned, so readers are not aware that it has occurred as an accidental in Alaska.

Another flaw is that the book's attractiveness is compromised by lumping colour plates together in sections. For example, located in the middle of the thrush family species accounts are 31 pages of colour plates of tanagers, thrush family, titmouse family, trogon, tropicbirds, troupial (American blackbird) family, turkey, vireo family and New World vultures and condors - rather a potpourri even though they are in alphabetical order. As with most undertakings of this magnitude other errors, mainly of editorial style, creep in. Under "Fecal Sac" we are referred to "Nests and Nestlings" but there is nothing on the sac there. A second reference under "Fecal Sac" is "Nest Sanitation"' which is there, but under that title we are referred further to "Young and Their Care" which contains a discussion of nest sanitation and fecal sacs. Further minor inconsistencies are the listing of "Courtship" with sub-topics such as courtship rituals but not courtship feeding. This latter appears as a completely separate topic followed by "Courtship Flight", which then only refers the reader back again to "Courtship" and "Flight".

Despite my less-than-total enthusiasm with the Encyclopedia, on balance Terres has done a remarkable job in producing a scientifically accurate tome relatively free of typographical errors. With over 7 million bird-watchers in the US alone (as of 1970), of which at least 3 million were considered to be seriously interested in field ornithology, there should be a receptive audience to savour this book.

Clayton M. White is a Professor of Zoology at Brigham Young University, Provo, Utah. 